Revista Herencia Vol. 29 (1), 51-62, 2016

Recibido 18-12-2015 Aprobado 12-01-2016

\title{
LAS ESCUELAS UNIVERSITARIAS Y SU IMPORTANCIA EN LA CREACIÓN DE LA UNIVERSIDAD DE COSTA RICA HACE 75 AÑOS: REFLEXIONES EN TORNO A LA EXPOSICIÓN "DE PARÍS A SAN JOSÉ, LA COLECCIÓN MÁS ANTIGUA DE LA UNIVERSIDAD DE COSTA RICA"
}

\section{Carolina Mora Ch.}

Máster en Historia de la Universidad de Costa Rica. Actualmente es profesora de Historia de la Cultura de la Escuela de Estudios Generales de la Universidad de Costa Rica. Durante su carrera ha impartido diversos cursos como Historia de las Instituciones de Costa Rica, Historia de Centroamérica, Historia de la Mentalidades Colectivas de Costa Rica e Historia de la Mentalidades Colectivas de América Latina. Desde el año 2007 dirige la Revista Estudios de la Sección de Historia de la Cultura de la Escuela de Estudios Generales de la Universidad de Costa Rica. cmora@tigomail.com

\section{RESUMEN}

Con la celebración de los 75 años del nacimiento de la Universidad de Costa Rica, institución de gran prestigio académico en el país y en la región latinoamericana, se valoraron, a nivel institucional y de la sociedad en general, los aportes que ha brindado esta institución a la sociedad. Esta conmemoración sirve de excusa para recordar la historia de la creación de la universidad y destacar el papel que cumplieron las diferentes escuelas universitarias, que ya existían en el país luego del cierre de la Universidad de Santo Tomás en 1888. Aun sin universidad, se mantuvieron abiertas algunas escuelas de educación superior. La Escuela de Bellas Artes, fundada en 1897, cumplió su misión durante muchos años y en 1940, junto a otras escuelas como Derecho, Farmacia, Agronomía, que habían funcionado por largo tiempo también, se unieron para dar vida a la recién creada institución de educación superior.

Como parte de las actividades conmemorativas en el año 2015, se hizo una profunda restauración de gran cantidad de modelos de yeso traídos de Francia para la apertura de la Escuela de Bellas Artes. El Museo Nacional ha albergado una hermosa exposición de dichos modelos que permiten retroceder a la Costa Rica de finales del siglo XIX y observar a través de ellos el pensamiento cultural de la época.

El importante esfuerzo económico que hizo el Estado costarricense en ese momento, con la traída de Tomás Povedano, forjador de este centro de estudios y la compra de estos yesos, denota un interés especial en la formación de jóvenes artistas que colaboraron en la decoración final del Teatro Nacional y que marcaron el devenir artístico y cultural de Costa Rica en la primera mitad del siglo XX.

Palabras clave: Universidad de Costa Rica, Universidad de Santo Tomás, Escuelas Universitarias, Escuela de Bellas Artes, aniversario 75.

\section{Abstract}

With the celebration of the 75th anniversary of the University of Costa Rica, an institution of great academic prestige in the country as well as in the latin american region, the contributions of this institution to the country at the institutional and social levels were assessed. This commemoration serves as an excuse to remember the history of the creation of the university an highlight the role that the different university schools played, since they already existed in the country after the closure of the University of Santo Tomas in 1888. Even without university, some schools of superior education stayed open. The School of Fine Arts, founded in 1897, fulfilled its mission for several years and in 1940, along with other schools like Pharmacy, Law and Agronomy helped create a new institution of superior education.

As part of the commemorative activities of 2015, a deep restoration of many gesso models that were brought from France for the opening of the Fine Arts School was made. The National Museum has a beautiful exhibition of such models that take the viewer back to the Costa Rica of the late XIX century and through them analyse the cultural thinking of the period. 
The important economic effort made by the Costa Rican government at the time was evidenced by bringing Tomas Povedano, forger of thus study center, and by buying these gessoes. This proved a special interest in forming young artists that collaborated with the final decoration of the National Theatre and that marked the artistic and cultural development of the early XX century of Costa Rica.

Key Words: University of Costa Rica, University of Santo Tomás, University Schools, Fine Arts School, 75th Anniversary.

\section{Introducción}

En mayo del 2015 la Universidad de Costa Rica ha celebrado por lo alto sus 75 años de existencia. Sin duda alguna fue un año en el que se ha reconocido desde lo académico hasta lo artístico, el aporte que ha dado esta institución a la sociedad costarricense. Nacida en los inicios de la década de 1940, ha sido testigo de grandes cambios en nuestro país, algunos de ellos, originados en su seno. En estos 75 años la Universidad ha generado una intensa vida académica, desarrollado un importante cúmulo de institutos de investigación científica, artística, social y cultural en general.

La Universidad de Costa Rica, activa en todos los procesos económicos y políticos que ha enfrentado el país desde 1940, se ha caracterizado por ser crítica y gestora de discusión de los mismos. No cabe duda de que ha sido catalogada como la más prestigiosa del país y orgullosamente exhibe altos estándares en los rankings latinoamericanos que califican la educación superior del subcontinente. Estos buenos resultados en su desempeño académico han sido producto no solo de la seriedad con que se imparte la docencia y se hace investigación, sino también de la fortaleza que tiene ésta en la acción social y extensión universitaria. Lo anterior gracias a que tradicionalmente ha contado con fondos estatales suficientes que le han permitido alcanzar un alto desempeño en estas tres áreas, docencia, investigación y acción social. Desde sus orígenes, el conocimiento, la búsqueda del bien común y las transformaciones necesarias para que nuestra sociedad alcance su pleno desarrollo, han sido su norte.

La universidad como cuerpo académico está comprometida integralmente en el proceso de la cultura, tanto de los individuos o personas que la componen, del todo constituido por sus organismos docentes o de investigación, como en lo que se refiere al desarrollo de la sociedad global, en donde se desenvuelve, o mejor, al perfeccionamiento integral de los individuos que constituyen esa sociedad (Barahona, 20015, p. 31).

Además, explica Luis Barahona, es el laboratorio de la cultura mundial, la responsable del desarrollo armonioso e integral de la personalidad, de proporcionar una cultura general de orden superior, para que los estudiantes se capaciten para pensar provechosamente. Pero esto no siempre fue así, el camino para que se pudiera establecer la universidad de Costa Rica pasó por varios momentos que recordaremos aquí de manera rápida.

\section{Cierre de la Universidad de Santo Tomás}

Al inicio de la década 1880, luego de la muerte de Tomás Guardia (1882) se produce la llegada al poder de Próspero Fernández (1882-1885) y, tras su muerte, lo sucede Bernardo Soto (1885-1886 y 1886-1890). Ambos militares, pero con espíritu civilista y sobre todo liberales. En sus gobiernos se fortalece el rumbo del Estado 
costarricense hacia el "progreso liberal" y positivista, tan en boga en América Latina y se privilegian las reformas a nivel educativo. La Ley General de Educación Común de 1885 que le dio fundamento a la Reforma Educativa, fue dirigida por Mauro Fernández.

No debe olvidarse que desde 1869 se había declarado la enseñanza primaria gratuita, obligatoria y costeada por el Estado. Unido a esto, se fueron abriendo, lentamente, varios colegios de secundaria. Se creó, entre otros, el Instituto Nacional (1874), que nació "bajo el alero de la Universidad de Santo Tomás" (Quesada, 2000, p. 372). Su creación obedeció, a la necesidad de que los jóvenes tuvieran acceso a una educación más pragmática y al hecho de que en la Universidad de Santo Tomás no había estudiantes preparados para los estudios profesionales. El Instituto Nacional fue cuidadosamente estructurado; su cuerpo docente fue compuesto por profesores europeos y se contrataron también docentes de la universidad. La orientación liberal del Instituto Nacional fue clara y su impronta se marcó en los dirigentes del país educados ahí.

La Universidad de Santo Tomás había sido instaurada desde el año 1844. Su estructura curricular comprendió los estudios menores o preliminares y los estudios mayores. Los menores comprendían gramática, castellana y latina, filosofía y matemática. Los estudios mayores fueron Teología, Derecho y Medicina, se podían seguir si se tenía el título de bachiller en filosofía. Al firmarse el Concordato con la iglesia Católica en 1852 se estableció que la Universidad de Santo Tomás sería declarada Pontificia, lo que le daba potestad al Obispo de actuar libremente en el nombramiento de profesores y directores de la Facultad de Teología, el Capellán y vigilar la enseñanza en otras áreas, a fin de que cumpliera "con las normas de la fe y la moral cristiana" (González, 1989, p. 59).

A lo largo de su existencia siempre se le achacó su poca relación con la realidad costarricense. Así que se intentó, una vez que Tomás Guardia llegó al poder, estructurar la educación media, para fortalecer la universitaria, tal y como lo había promovido años antes José M. Castro Madriz (González, 1989, p.66). Esto se hizo, a costa de la Universidad de Santo Tomás, a la que se le adjuntó el Instituto Nacional. Por decreto se fundó el instituto dentro de la propia Universidad y se le cargó a su presupuesto. Solo sobrevivieron las Cátedras de Derecho, ya que toda la fuerza económica y académica se lanzó hacia el Instituto Nacional a partir del 16 de mayo de 1875. Comenta Paulino González que la Universidad en este cambio perdió hasta el edificio, ya que pasó a alquilar una casa en las cercanías.

Una nueva intención de reestructurar la Universidad de Santo Tomás se dio en 1883. Se propuso entonces la creación de un Instituto Universitario, que sustituyó al Instituto Nacional y sobrevivió la enseñanza del Derecho. Por estas razones, queda claro que el cierre de la Universidad de Santo Tomás no fue una tarea difícil.

Aparte de las condiciones estructurales de la enseñanza general en Costa Rica, que era muy deficiente en los niveles de primaria y secundaria, la falta de motivación de los estudiantes para ingresar a la universidad era notoria. Los niveles de analfabetismo eran alarmantes a finales del siglo XIX, de alrededor de un $65 \%$, indica Juan Rafael Quesada (2000, p.378), sin embargo el mismo autor resalta el valor en la vida nacional de todos aquellos costarricenses formados en la aulas de la Universidad de Santo Tomás, muchos de ellos políticos, comerciantes, profesores, maestros, geómetras, médicos, etc.

Tras la llegada de Mauro Fernández a la Secretaría de Instrucción Pública y la Secretaría de Hacienda, se elaboró la "Ley Fundamental de Instrucción Pública" (1885). Junto a colaboradores de alto nivel académico como Carlos Gagini, Buenaventura Corrales, Miguel Obregón y otros, se dispuso iniciar una importante reforma educativa a partir de 1886. 
Alegándose que la Universidad de Santo Tomás era básicamente un edificio, que no contaba con un sistema de estudios y programas adecuados a las necesidades del país y que además, salía muy oneroso su mantenimiento para el Estado, se propuso el cierre de la institución, el 20 de agosto de 1888.

Con la extinción de la Universidad de Santo Tomás no cabe duda de que se perdió en primer lugar, el espíritu universitario que tanta falta nos hace en la universidad actual, donde no logramos todavía comprendernos en el diálogo por la superación de los valores estrictamente culturales, en función con el desarrollo de la actual universidad y todas las que en el futuro se creen, sentirán siempre ese vacío en su seno, aun cuando logren modernizar al máximo las estructuras que podríamos llamar objetivas, pues la tradición no se improvisa, sobre todo si es posible recoger en ella los valores auténticos, la experiencia positiva que dejan tras de sí las instituciones (Barahona, 2015, p.10).

\section{Creación de Escuelas de Educación Superior}

Al cerrarse la Universidad de Santo Tomás, siguió funcionando la Escuela de Derecho y se le dio un mayor impulso a la educación primaria y secundaria. Las pocas escuelas universitarias que se crearon entre 1888 y 1940, año en que se estableció la Universidad de Costa Rica, funcionaron bajo la dirección de los colegios de profesionales en la materia. Así que el Protomedicato creado en 1857, fue el que administró la Facultad de Medicina, Cirugía y Farmacia en agosto de 1895. El Protomedicato tuvo bajo su vigilancia a los médicos, dentistas, farmacéuticos y obstetras del país. La Facultad de Medicina fue de corta vida, pero en 1897 se fundó la Escuela de Farmacia, que desde 1902 estuvo bajo la dirección del Colegio de Farmacéuticos, fundado en ese año (Quesada, 2000, p. 401).

En 1897 se estableció la Escuela Nacional de Bellas Artes. Su fundación concuerda con la inauguración del Teatro Nacional en ese mismo año. Siguiendo los cánones culturales de la época, se trajo al país a Tomás Povedano y Arcos, (1847-1943) un español nacido en Córdoba, quien había sido contratado en Quito para fines similares a los que concretó en Costa Rica. "Povedano era un hombre de gran experiencia docente quien se había encargado anteriormente de la fundación de dos escuelas de arte en Cuenca y Guayaquil, Ecuador" (Escuela de Bellas Artes, 1997) Pero en Ecuador estalló la llamada revolución del 5 de junio, que llevó al poder a Eloy Alfaro y Povedano salió en ese momento. El pintor aceptó la invitación que le hizo Rafael Iglesias de asumir la dirección de la Escuela de Bellas Artes, que se encargaría de proveer de artistas al país y sobre todo de finalizar las tareas de decoración del recién finalizado Teatro Nacional.

La Escuela Nacional de Bellas Artes fue inaugurada el 12 de marzo de 1897 (Fumero, 2005, p. 34) por medio del Decreto N.6 y se estableció como dependencia de la Secretaría de Instrucción Pública. Funcionó en las antiguas instalaciones de la Universidad de Santo Tomás. El método de enseñanza aplicado fue el "Arte Académico", es decir, un método que reproduce enseñanzas del arte clásico grecorromano, muy acorde a los gustos de la élite costarricense seguidora de los cánones culturales europeos, centrados en los estilos clásico y neoclásico, asociados a la idea de progreso y civilización.

La creación de esta institución es significativa, teniendo en cuenta que durante este período se fundan una serie de instituciones de carácter nacional, como el Teatro (1897), el Museo (1887) y el Archivo (1881). Además, se erigen dos monumentos que inciden en el imaginario costarricense, en tanto participan de la conformación de 
un discurso nacionalista: el Monumento a Juan Santamaría (1891) y el Monumento Nacional (1895). Contemporáneamente a la creación de la Escuela Nacional de BeIlas Artes en Costa Rica, se fundaron academias de bellas artes a lo largo de América Latina (Raabe, 2012, p. 95).

Se debe agregar que en Costa Rica además por la misma época se fundó la Biblioteca Nacional, preocupación de don Miguel Obregón por el rescate de la biblioteca de la Universidad de Santo Tomás, el Instituto Físico Geográfico, el Registro Civil y otras instituciones que aun hoy brindan apoyo al desarrollo nacional y fueron visionarias propuestas modernizantes del grupo liberal al mando de la nación.

Esta Escuela superior desde un inicio fue muy polémica, en primer lugar, su director fue un extranjero, en segundo lugar, los altos costos para un país tan pobre y en tercer lugar, que no había ni escuela normal para formar maestros de primaria y se tenía un escuela de bellas artes. En fin, no cabe en este artículo discutir el tema, solo se esboza, pues en 1902 casi se cierra esta institución artística y muchos opinaron a favor de esto. Sin embargo, sobrevivió y fue una de las primeras en pasar a formar parte de la Universidad de Costa Rica en 1940.

Para iniciar las labores de enseñanza, se encarga un conjunto de yesos y láminas con dibujos impresos.

Posiblemente, haya sido don Tomás Povedano, quien como director de la escuela, haya requerido su compra. Los yesos, así como los dibujos, fueron adquiridos con fines didácticos, dado que la Escuela Nacional de Bellas Artes adoptó como método de enseñanza el sistema francés conocido como Mèthode Julien, el cual se basaba en la copia directa de reproducciones de obras paradigmáticas del arte occidental, especialmente de la Antigüedad Clásica para el aprendizaje del dibujo (Raabe, 2012, p. 95)

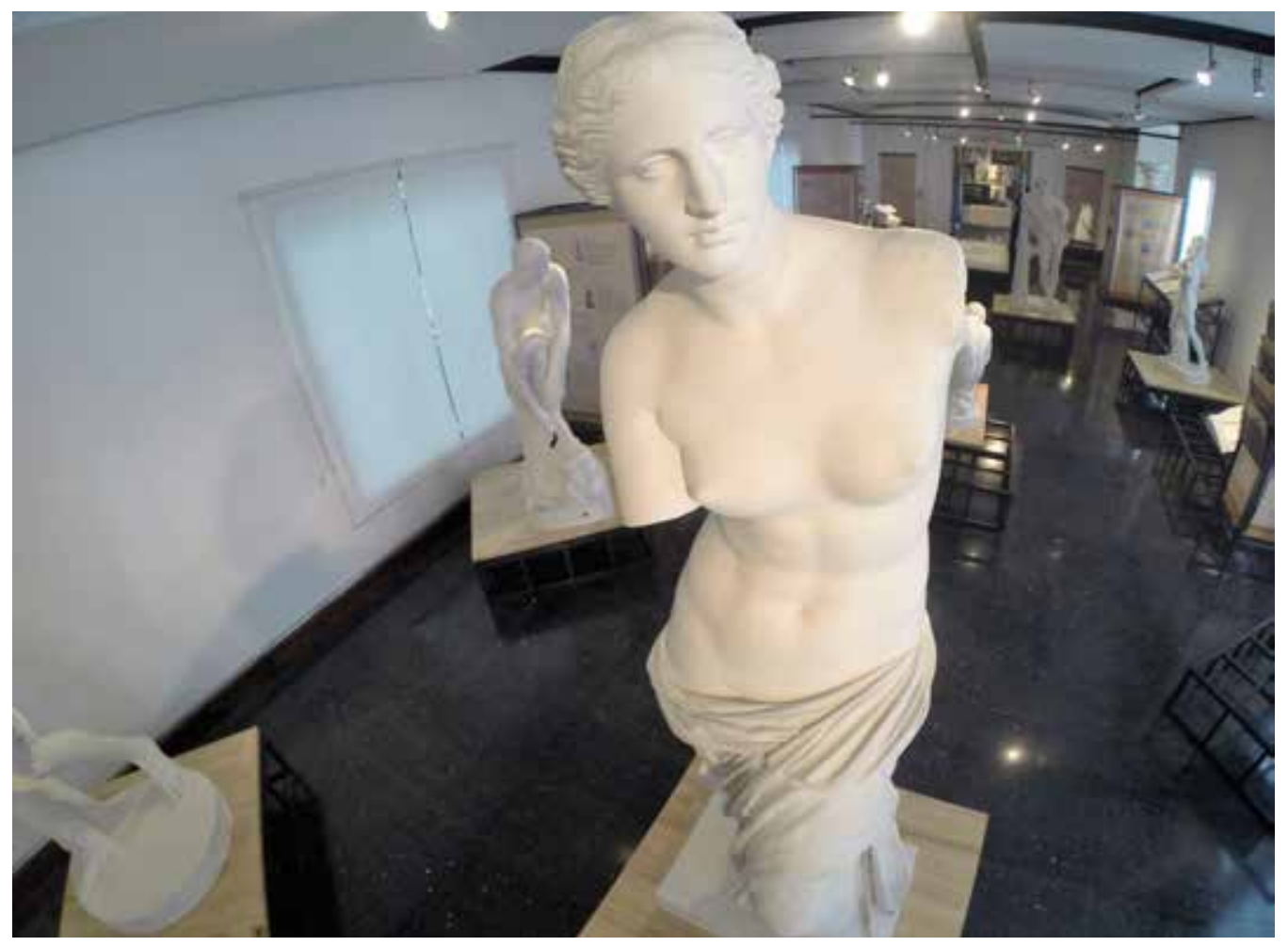


Fueron compradas al Taller de Vaciados de la Reunión de Museos de Francia (Musées Nationaux Moulage) (Raabe, 2102, p. 96), encargado de la reproducción de la rica colección escultórica del Museo del Louvre. La colección constaba de 352 esculturas, actualmente se conservan 211 y las litografías, 1442 láminas, de las cuales se conservan 923.

El pensamiento modernista europeo, que se buscaba estimular en la cultura nacional, fue muy importante para la formación de los estudiantes de la escuela de artes, a nivel ideológico y cultural. Por sus aulas pasaron gran cantidad de profesores de artes plásticas de escuelas y colegios. Aunque como bien dice Laura Raabe:

Se da la inserción a un proceso civilizatorio que, en última instancia, generaría una serie de tensiones, evidentes en el plano social y en el político, y que en el cultural nos obliga a señalar la ironía palpable en el fenómeno de fundación de academias en Latinoamérica, precisamente cuando la validez de estas estaba siendo cuestionada por las nuevas vanguardias en Europa (Raabe, 2102, p. 97).

En 1940, cuando se fundó la Universidad de Costa Rica la Escuela Nacional de Bellas Artes se une a la institución de educación superior. La primera decana de la Facultad de Bellas Artes fue Ángela Castro Quesada (1884-1954), pintora y pianista, quien estuvo a la cabeza dicha institución entre 1940 y 1942. A partir de 1942 el decano fue el arquitecto y pintor Teodorico Quirós Alvarado (1897-1977), quien se dedica a una transformación profunda de los planes de estudio de la Facultad. El objetivo de los nuevos programas es poner a los estudiantes en contacto con su realidad social, darle nuevos instrumentos técnicos con que expresarse e introducirlos en el conocimiento de las corrientes artísticas más recientes y contemporáneas.

\section{Otras escuelas}

El origen de la Escuela de Enfermería, se encuentra en la fundación de la Escuela de Obstetricia en 1899. Posteriormente en 1917 se creó la Escuela de Enfermería en el Hospital San Juan de Dios, bajo la dirección de la Facultad de Medicina, nombre que recibía el actual Colegio de Médicos y Cirujanos. La Escuela de Enfermería y la de Obstetricia funcionaban separadamente bajo la dirección del presidente de la Facultad de Medicina, pero se permitía que las obstétricas ingresaran a la Escuela de Enfermería y las enfermeras a la de Obstetricia. Posteriormente se fusionarían ambas escuelas, con un plan de estudios de tres años (el último para obstetricia), otorgando al finalizar el diploma de Enfermera y Obstétrica.

Durante largo tiempo se entrenó a las parteras empíricas de zonas rurales y se evitaron así muchos problemas de salud materno-infantil. Aunque es indudable el aporte que estas escuelas hicieron a la salud de las madres y sus hijos, a partir de 1945 que se busca mejorar la preparación del personal de enfermería nacional y la Organización Mundial de la Salud ofrece apoyo y estudia la situación de la enfermería en Costa Rica. En 1951 se firma un convenio con la Organización Panamericana de la Salud y con la Organización Mundial de la Salud en el cual se comprometen a ayudar:

Con personal técnico para la instrumentación de un plan de estudios moderno en enfermería.

Con un programa de Becas para adiestrar enfermeras nacionales en pedagogía en enfermería y especialista en algún área de enfermería. 


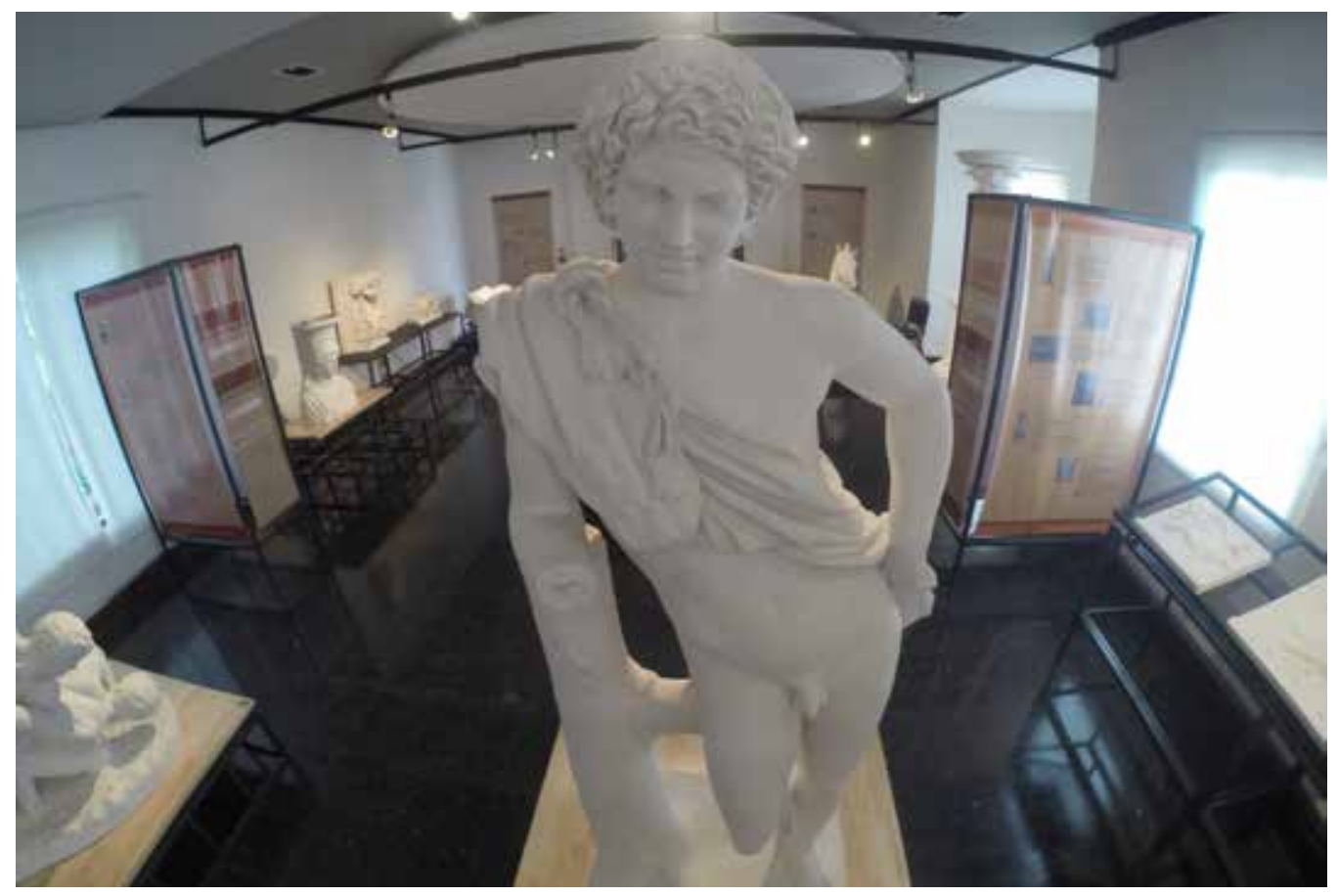

Foto 2. Apolo, de Belvedere. (Fotografía de Isabel Sobrado)

Con Material didáctico y equipo de laboratorio para la enseñanza de la enfermería.

(http://www.enfermeria.ucr.ac.cr/index.php/escuela/historia).

A partir del año 1951 la Escuela de Enfermería se independizó del Colegio de Médicos y Cirujanos de Costa Rica, pero no fue sino hasta 1966 que se incorporó a la Universidad de Costa Rica, como escuela afiliada a la Escuela de Medicina. En el año 1972 se convirtió en Escuela Anexa de la Facultad de Medicina y en 1977 se aprobó la división de la Facultad de Medicina en Escuelas: la Escuela de Medicina y la Escuela de Enfermería. Hoy ocupa un bello edificio ubicado en la Ciudad de la Investigación.

Desde el cierre de la Universidad de Santo Tomás se vio de la necesidad de establecer una escuela de agricultura en el país, motivo por el cual Pedro Pérez Zeledón visitó varios países de Europa y Estados Unidos para estudiar los programas de las carreras universitarias. Sin embargo, esto no sucedió hasta 1926, cuando por decreto se creó la Escuela de Agricultura. Carlos Monge explica que "como hasta ese momento no existía Colegio de Agrónomos, ni Ministerio de Agricultura, se adscribió la Escuela al Ministerio de Fomento" (Monge, 1978, p. 85). Los cursos prácticos se impartieron en una finca en San Pedro Montes de Oca. Hoy se encuentra ahí la Sede Rodrigo Facio de la Universidad de Costa Rica.

La Escuela Nacional de Agricultura para 1940, con la fundación de la Universidad de Costa Rica, pasó a convertirse en la Facultad de Agronomía. "Así pasan a ser patrimonio de la Universidad la finca y las instalaciones en las que venía funcionando desde 1927 (Facultad de Agronomía, http://www.agro.ucr.ac.cr/historico/hs.html). Luego se adquieren los terrenos de la Estación Fabio Baudrit en la Garita de Alajuela (1955) y otros terrenos o estaciones experimentales e institutos de investigación. Actualmente se denomina Facultad de Ciencias Agroalimentarias. 


\section{La Universidad de Costa Rica: 1940-2015}

Mucho se ha escrito sobre la apertura de la Universidad de Costa Rica en 1940 bajo el gobierno de Rafael Ángel Calderón Guardia y con Luis Demetrio Tinoco como Secretario de Educación, quien se empeñó en abrirla, a pesar de que el mundo se encontraba en plena II Guerra Mundial, lo cual significaba crisis en Costa Rica.

Desde 1935 con la llegada de la Misión Pedagógica Chilena al país (Monge, 1978, p. 92), se hizo un profundo estudio de las necesidades educativas de Costa Rica en los tres sectores, primaria, secundaria y universitaria. Era más que sentida la necesidad de una universidad para la sociedad costarricense. Cinco años después, un 26 de agosto se firmó el decreto de creación de la Universidad de Costa Rica. Su organización estuvo casi que en su totalidad acorde a lo estipulado por Luis Galdámes, el jefe de la Misión Chilena. Su libro La Universidad Autónoma, surgido del trabajo en Costa Rica "no tuvo parangón en América Latina" (Monge, 1978. P. 92).

Desde sus orígenes, la Universidad de Costa Rica fue autónoma y con plena capacidad jurídica para adquirir derechos y contraer obligaciones. Su apertura se inició con las Escuelas de Derecho, Farmacia y Agricultura. Se incorporó la Escuela Normal (pedagogía) y la Escuela de Bellas Artes y se creó la Facultad de Filosofía y Letras, Ciencias e Ingeniería. En 1942 se fundó la Facultad de Odontología y en 1943 se creó la Facultad de Ciencias Económicas y Sociales. Con su fundación se abrió un nuevo capítulo en la vida educativa nacional. En ella se han formado la mayor parte de los hombres y mujeres que han dirigido al país en las últimas cinco décadas.

Se han dado grandes reformas como la de 1957, en la que se crearon los Estudios Generales que permitieron el fortalecimiento humanístico de la Universidad. También nacieron nuevas facultades, como Medicina (1961) y como Ciencias Sociales (1972) Nuevas carreras profesionales y la diversificación de las escuelas ya existentes, modernizan constantemente el ámbito universitario, así como la apertura de nuevas maestrías y doctorados que ayudan a la especialización de los estudiantes.

La universidad ha extendido sus funciones por todo el país, creando varias sedes regionales y abriendo oportunidades para educación abierta de niños y adultos. Las Residencias Estudiantiles han permitido, desde hace décadas, que muchos estudiantes de zonas alejadas del país puedan acceder a la educación superior. Su sistema de becas favorece la formación de excelentes profesionales, que de otro modo no podrían haber costeado sus estudios.

Foto 3. Frisos (Fotografía de Isabel Sobrado)

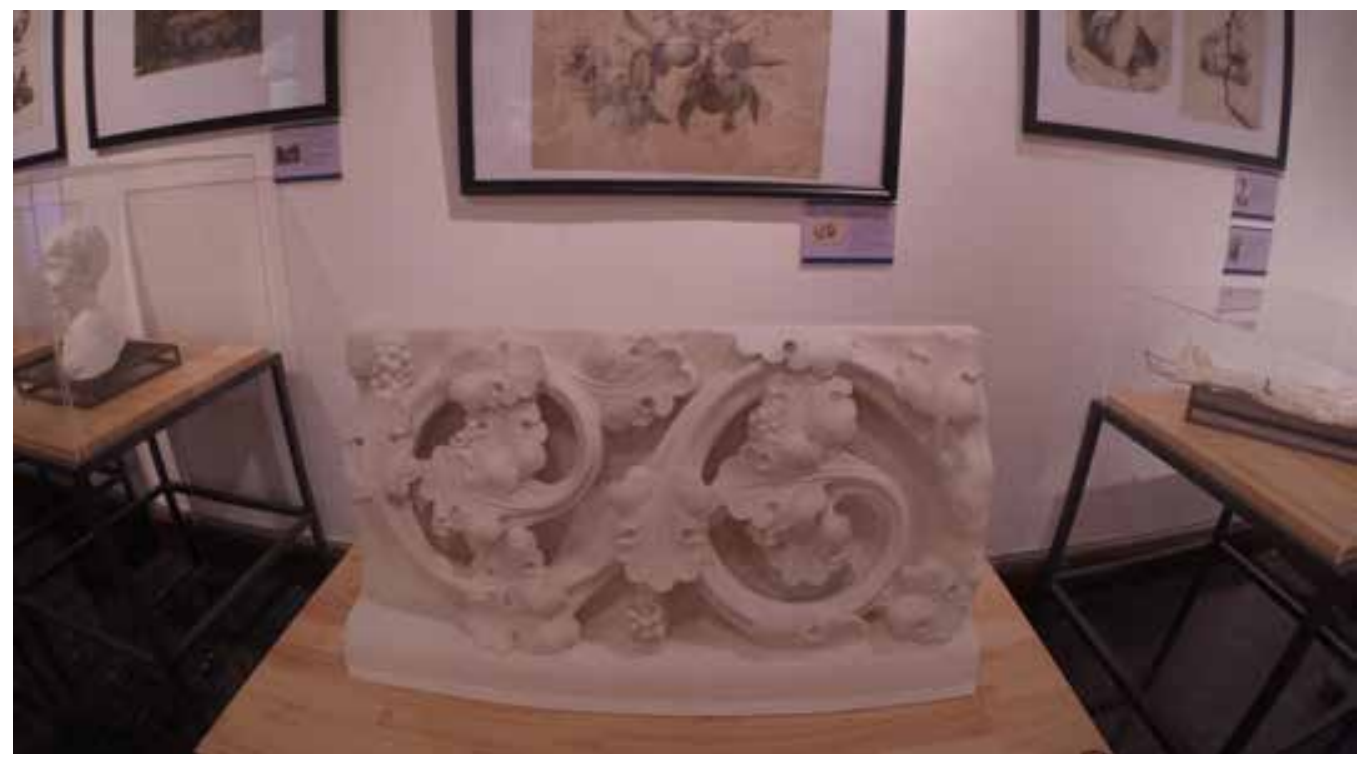


En este aparte es fundamental mencionar como un punto medular en el quehacer de la universidad la investigación, respaldada por más de cien institutos de investigación que abarcan un sinnúmero de áreas: ciencias naturales, sociales, economía, artes, lenguas, etc.

La celebración de estos 75 años de vida de una institución como la Universidad de Costa Rica permitió tomar una mayor conciencia del valor histórico y cultural de este patrimonio académico. Por esta razón es de vital importancia seguir estudiando las múltiples formas en las que se debe continuar fortaleciendo y reformando a la decana de la educación superior costarricense.

\section{Conclusión: Los yesos y litografías de Bellas Artes: un rescate conmemorativo del 75 aniversario de la Universidad de Costa Rica}

La llegada al país de Tomás Povedano (1847-1943), "pintor oficial de la élite política de Costa Rica" (Solano y Chacón, 2014, p.11), como director de la Escuela de Bellas Artes (1897), coincidió con la consolidación del Estado Liberal, como se vio. Desde la década anterior se fortaleció por vía de la educación una visión de mundo eurocentrista, civilizadora y de progreso nacional.

Povedano se instaló con su Escuela en lo fue el edificio de la Universidad de Santo Tomás e inició la formación de un importante grupo de alumnos, algunos de ellos destacados pintores nacionales. Con su llegada fueron traídos al país los yesos y litografías franceses de los que ya se habló.

A Povedano lo seguía la fama desde Sevilla, España, Quito y Cuenca en Ecuador y pronto se incorporó de lleno a la élite intelectual y política costarricense, con la que compartió intereses en común, visión de mundo y la masonería.

"De París a San José, la colección más antigua de la Universidad de Costa Rica", exposición en el Museo Nacional, inaugurada en noviembre de 2015 como parte de la conmemoración de los 75 años de la creación de la universidad, muestra al público las bases culturales sobre las que se instaló un centro de estudios académicos de las bellas artes en Costa Rica. Sin lugar a dudas el conjunto de yesos y dibujos litografiados sorprende a los visitantes por su cantidad y calidad, así como por lo ajeno a la realidad de la Costa Rica de fines del siglo XIX. L:

En esa época, el taller de vaciados fue absorbido por la École Nationale et Spéciale des Beaux-Arts que realizaba reproducciones de esculturas y relieves para las academias francesas - principalmente - como un eficaz instrumento académico y para los estudios estilísticos de los arquitectos y artistas. Se utilizaba, entonces, el yeso para reproducir las obras a partir de moldes de las esculturas de la antigüedad (Zamora, 2014, p. 37)

La exposición es parte de un retrato del pensamiento del momento en que se inauguró la Escuela Nacional de Bellas Artes. Los miembros de la élite costarricense, educados muchos de ellos en Europa, aspiraban a alcanzar a nivel social y económico y hasta político, los más altos valores de occidente (Francia, Inglaterra, Bélgica, etc.). La Academia, reprodujo en sus estudios los modelos grecorromanos de las artes plásticas y los cánones de belleza de la época.

Setenta y cinco años del nacimiento de la Universidad de Costa Rica son un excelente motivo para recordar los orígenes de su fundación y el papel que tuvieron esas primeras Escuelas Superiores en la concreción de un proyecto universitario moderno. 
Foto 4. Vista general de la exposición (Fotografía de Isabel Sobrado)

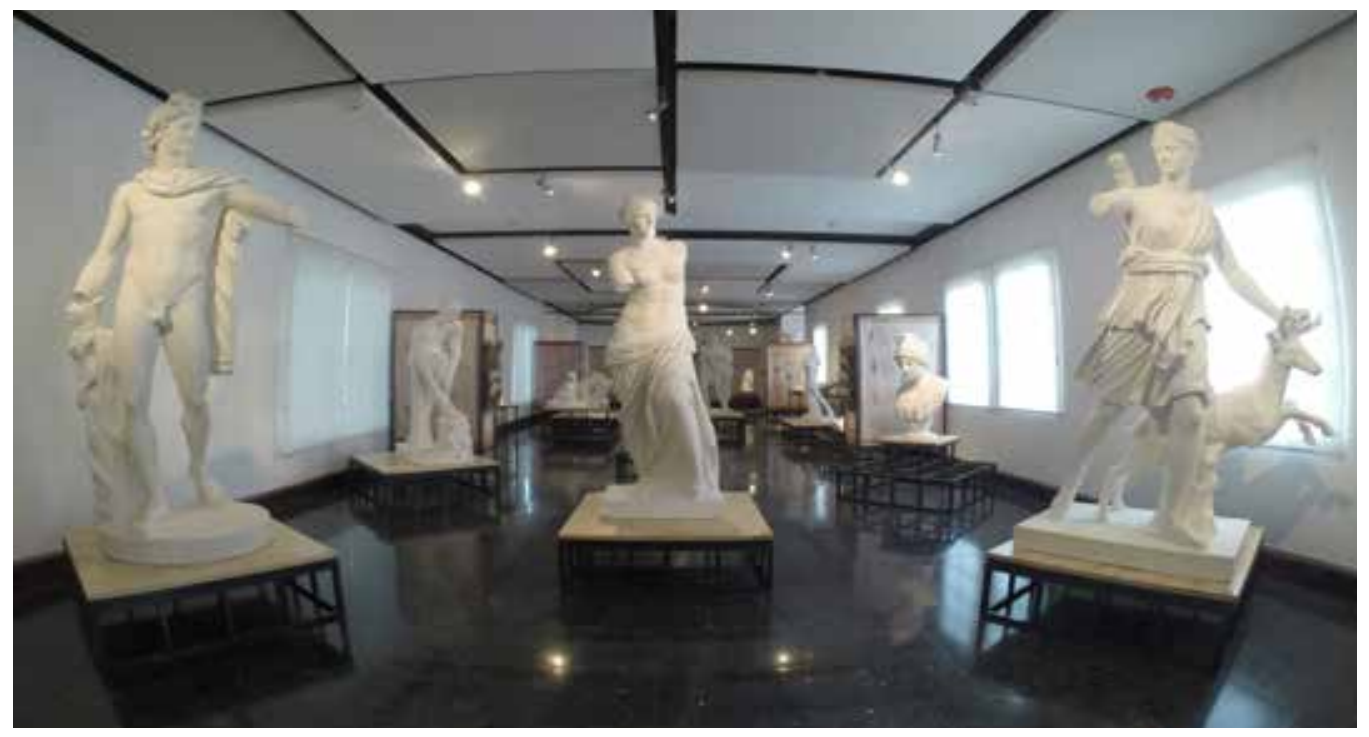

La colección de yesos traídos de Francia para el desarrollo de la Academia de Bellas Artes cuenta también algo de la historia de la universidad. Es importante resaltar en esto el esfuerzo del Museo de la Universidad de Costa Rica (museo+UCR) y de la Escuela de Artes Plásticas. La exposición exhibida en el Museo Nacional de Costa Rica es así mismo una gran oportunidad, para que el pueblo costarricense conozca y valore esta herencia y comprenda los esfuerzos emprendidos, desde hace muchos años en pro del desarrollo cultural nacional.

\section{Blbliografía}

Barahona, Luis (2015) La Universidad de Costa Rica (1940-1973). San José: Editorial de la Universidad de Costa Rica.

Escuela de Artes Plásticas (1997) Catálogo del Centenario de La Escuela Nacional de Bellas Artes, 1897-1997. San José: Museo de Arte Costarricense y Escuela de Artes Plásticas de la Universidad de Costa Rica.

Escuela de Enfermería (2016) http://www.enfermeria.ucr.ac.cr/index.php/escuela/ historia

Facultad de Ciencias Agroalimentarias. (2016) http://www.agro.ucr.ac.cr/historico/ hs.html

Fischel, Astrid (1987) Consenso y represión. Una interpretación socio-política de la educación costarricense. San José: Editorial Costa Rica.

Fumero, Patricia (2005).Cultura y sociedad en Costa Rica 1914-1950. San José: Editorial de la Universidad de Costa Rica.

Fumero, Patricia (2000) "Vida cotidiana en el Valle Central: 1850-1914. Los cambios asociados con la expansión del café". En: Botey, Ana María (Coordinadora) Costa Rica desde las sociedades autóctonas hasta 1914. San José: Editorial de la Universidad de Costa Rica.

González, Paulino (1989) La Universidad de Santo Tomás. San José: Editorial de la Universidad de Costa Rica.

Monge, Carlos (1978) Universidad e Historia. San José: Ministerio de Cultura Juventud y Deportes.

Museo de Arte Costarricense (1995) Teodorico Quirós. San José: Museo de Arte Costarricense.

Quesada, Juan Rafael (2000) "La educación en Costa Rica: 1821-1914" En: Botey, 
Ana María (Coordinadora) Costa Rica desde las sociedades autóctonas hasta 1914. San José: Editorial de la Universidad de Costa Rica.

Raabe, Laura (2012) "Los Antiguos Yesos de Bellas Artes" En: Káñina, Revista de Artes y Letras, Universidad de Costa Rica XXXVI (Extraordinario): 95-98, 2012.

Solano, Vivian y Chacón Manuel. (2014) Tomás Povedano y los billetes de Costa Rica. San José: Fundación Museos Banco Central.

Zamora, Herberth (2014) "La conservación y restauración de la Gipsoteca de la Escuela de Artes Plásticas de la Universidad de Costa Rica". En: Humanidades, Revista de la Escuela de Estudios Generales de la Universidad de Costa Rica, Vol.4: 37-43, 2014. 
Revista Herencia Vol. 29 (1), 2016 